\title{
Evaluating the Efficacy of Lysozyme Against Lactic Acid Bacteria Under Different Winemaking Scenarios
}

\author{
M. Azzolini ${ }^{1}$, E. Tosi ${ }^{1}$, G. Veneri ${ }^{2}$, G. Zapparoli ${ }^{*}$ \\ (1) Centro per la Sperimentazione in Vitivinicoltura, Provincia di Verona, Servizio Agricoltura, Via della Pieve 64-37020 San Pietro in \\ Cariano - Verona, Italy \\ (2) Dipartimento di Biotecnologie, Università degli Studi di Verona, strada Le Grazie 15, 37134 Verona, Italy
}

Submitted for publication: January 2010

Accepted for publication: May 2010

Key words: Lysozyme, Lactobacillus brevis, Oenococcus oeni, winemaking, malolactic fermentation

\begin{abstract}
This study evaluated the efficacy of lysozyme in winemaking to control lactic acid bacteria (LAB). In a winery vinification, indigenous LAB were partially and completely inhibited when lysozyme was added to red and white grape must respectively. This result was confirmed by using two selected strains of Lactobacillus brevis and Oenococcus oeni to contaminate the grape must. In the red wine microvinification, the cell population decreased only temporarily and malolactic fermentation terminated at different times, depending on the grape must $\mathrm{pH}$ and lysozyme dosage. In the white wine microvinification, cell mortality rates differed according to lysozyme dosage rather than pH values. During the fermentation, lysozyme activity was stable or decreased, depending on the absence or presence of grape must respectively. The study highlighted that lysozyme efficacy is strongly affected by the type of vinification.
\end{abstract}

\section{INTRODUCTION}

Lysozyme is a natural protein with bactericidal activity against Gram-positive bacteria, including lactic acid bacteria (LAB). The use of this enzyme has been shown to be an effective antimicrobial in many foods (Hughey \& Johnson, 1987). In the winemaking process, hen egg lysozyme is utilised to control spontaneous LAB growth that often causes spoilage or stuck fermentation (Gerbaux et al., 1999; Delfini et al., 2004; Bartowsky, 2009). The benefits derived from the control of wine spoilage LAB are mainly the reduction in the risk of increased volatile acidity, as well as an increase in biogenic amines. The main technological interest of lysozyme is to reduce the traditional use of sulphur dioxide, which can cause health concerns in consumers (Bartowsky, 2009; Sonni et al., 2009).

It has been ascertained that the efficacy of lysozyme in inhibiting undesirable $\mathrm{LAB}$ varies according to species and winemaking conditions (Gerbaux et al., 1999; Gao et al., 2002). Several strains, which are potentially detrimental to wine quality, are resistant to this enzyme (Delfini et al., 2004). A lytic cocktail of Streptomyces spp., assayed to control LAB and acetic acid bacteria, was described as a valid alternative to lysozyme because of its higher activity against resistant strains (Blättel et al., 2009). Moreover, lysozyme is less active in red vinification than in white, although it has been demonstrated that its activity is not compromised in the former (Bartowsky \& Hensche, 2004; Delfini et al., 2004). Isabel et al. (2009) reported the use of lysozyme as being very beneficial to maintain low histamine levels and ensure Oenococcus oeni implantation in red vinification. Nevertheless, Tirelli and De Novi (2007) proved that lysozyme is unstable in young red wine, thus doubting its effectiveness in controlling malolactic fermentation (MLF). Although lysozyme does not seem to cause important changes in wine aroma, high amounts of this antimicrobial agent could increase the risk of colour instability and the formation of precipitate (Bartowsky \& Hensche, 2004). Weber et al. (2007) did not exclude adverse allergic reactions to wines treated with lysozyme, but, for Kirschner et al. (2009), this risk is avoided if the wines are filtered. Moreover, the use of lysozyme involves significant additional costs for winemakers (enzyme purchase, clarification and fining procedures).

Although the use of lysozyme was approved by the Office International de la Vigne et du Vin (OIV) more than a decade ago, some questions remain open. The recommended lysozyme dosage is too generic because it does not consider that lytic activity is strongly affected by contingent winemaking conditions. Hence, from the applied point of view, a more thorough evaluation of its efficacy in defined oenological environments would be informative.

This study evaluated the effects of lysozyme added to grape must for controlling LAB growth. Before alcoholic fermentation, microbial spoilage can be favoured by the vinification of defective grapes together with high $\mathrm{pH}$ and temperatures (Ribéreau-Gayon et al., 2006). Two indigenous strains of Lactobacillus brevis and $O$. oeni were used in grape musts as contaminant bacteria in laboratory-scale winemaking trials. L. brevis is one of the most important wine spoilage LAB, while the uncontrolled growth of indigenous $O$. oeni strains is often undesirable. The activity of the muramidase was evaluated in terms of must $\mathrm{pH}$ and its dosage. The different results from the red and white vinifications are lastly discussed.

\section{MATERIALS AND METHODS}

\section{Strains, identification and culture conditions}

The strains used in the vinifications were Lactobacillus plantarum DB7 and DB13, L. hilgardii DB19, L. brevis DB12 and Oenococcus oeni DB3, isolated from grape must at the 
Centro per la Sperimentazione in Vitivinicoltura, Provincia di Verona (Italy) and deposited in the culture collection of the Dipartimento di Biotecnologie of the University of Verona (Italy). These strains were isolated from fermenting juice to produce Valpolicella and Soave wine, and their identification was carried out by a classification based on morphological and biochemical tests, such as Gram staining, catalase reaction, and carbohydrate fermentations (data not shown). Coccal-shaped isolates were shown through species-specific PCR to belong to $O$. oeni, according to Zapparoli et al. (1998). Rod-shaped isolates were analysed for the identification of Lactobacillus plantarum by species-specific PCR according to Torriani et al. (2001). Strains were grown aerobically in FT80 at pH 5.3 (Cavin et al., 1989) and $28^{\circ} \mathrm{C}$ and used at the late exponential phase for biochemical and molecular assays. Purified LAB cultures were maintained at $-80^{\circ} \mathrm{C}$ in the same medium supplemented with glycerol $25 \%$ $(\mathrm{v} / \mathrm{v})$.

\section{Lysozyme}

The lysozyme used in all the experiments was a food grade commercial product (Lallzyme Lyso, Lallemand Inc., Montreal, Canada).

\section{Analysis of must and wine}

The musts were analysed at the time of crushing, and the wine samples were collected during and after AF and MLF. Ethanol was analysed by NIR spectroscopy using Alcolyzer Wine apparatus (Anton Paar GmbH, Graz, Austria). The sugar content was determined by the Fehling method with automatic titration (Crison, Alella, Spain). Total acidity (expressed as tartaric acid) was determined by titration with $0.1 \mathrm{NaOH}$ to an end point of $\mathrm{pH}$ 7.0. Total and free $\mathrm{SO}_{2}$ were determined iodometrically by the Ripper procedure (Ough \& Amerine, 1988). L-malic acid and L-lactic acid were quantified using enzyme kits (La Roche, Basel, Switzerland). The total phenolic contents of must-wine were determined with Folin-Ciocalteu reagent, using gallic acid as standard (Singleton \& Rossi, 1965). Total anthocyanins were determined by the Glories method (Glories, 1979), using malvidin3 -glucoside as standard. The colour intensity of the must-wine was determined by summing absorbances at 520 and $420 \mathrm{~nm}$ of diluted samples (two- to 10-fold) on aqueous solution containing $50 \mathrm{mM}$ tartaric acid and $35 \mathrm{mM} \mathrm{NaOH}$.

\section{Vinifications in the winery}

Two vinifications, a red and a white, to produce Valpolicella and Soave wine respectively, were carried out to evaluate the effect of lysozyme on indigenous LAB growth. Every vinification was prepared by crushing the grapes and the resulting liquid (juice) was divided into aliquots without previous must clarification. In the case of the red vinification, the solid fraction (grape pomaces) were separated from the juice, mixed and subsequently divided into the proper proportion in order to obtain homogenous trials. The volume of each single trial was $150 \mathrm{~L}$ for both vinifications. The musts were sulphited by adding $50 \mathrm{mg} / \mathrm{L} \mathrm{SO}_{2}$. The composition of the red grape must was: $\mathrm{pH} 3.29$, reducing sugars $20.6^{\circ} \mathrm{Brix}$, total acidity $6.00 \mathrm{~g} / \mathrm{L}$ as tartaric acid, acetic acid $0.09 \mathrm{~g} / \mathrm{L}$, and L-malic acid $1.58 \mathrm{~g} / \mathrm{L}$. The composition of the white grape must was: $\mathrm{pH} 3.51$, reducing sugars $20.8^{\circ}$ Brix, total acidity 5.30 $\mathrm{g} / \mathrm{L}$ as tartaric acid, acetic acid $0.03 \mathrm{~g} / \mathrm{L}$, and L-malic acid 1.84 $\mathrm{g} / \mathrm{L}$. The amount of lysozyme added to the grape musts was 150

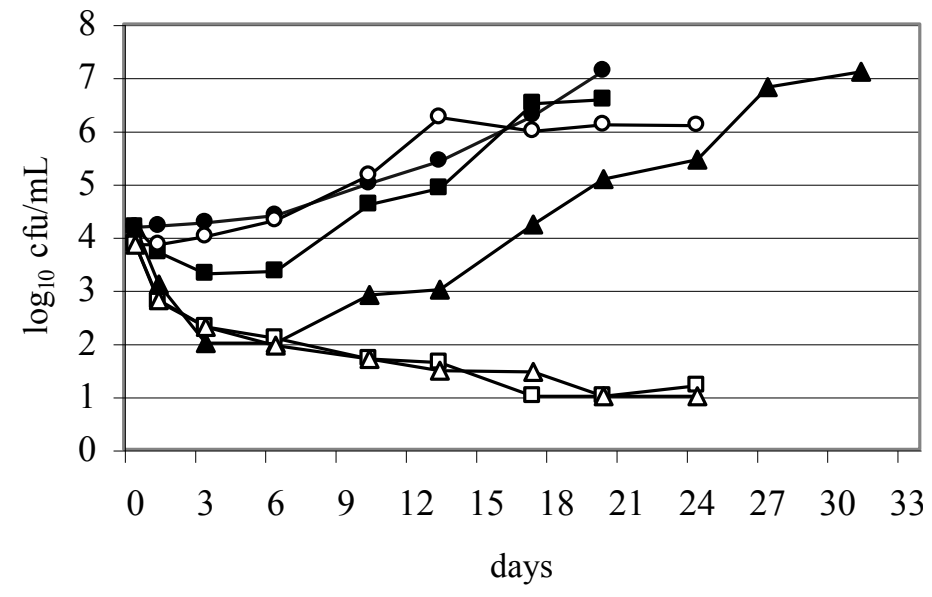

FIGURE 1

Spontaneous LAB population (cfu/mL, ) measured during a red (full symbols) and white (empty symbols) vinification adding 0 (circle), 150 (square) and 300 (triangle) $\mathrm{mg} / \mathrm{L}$ of lysozyme to grape must.
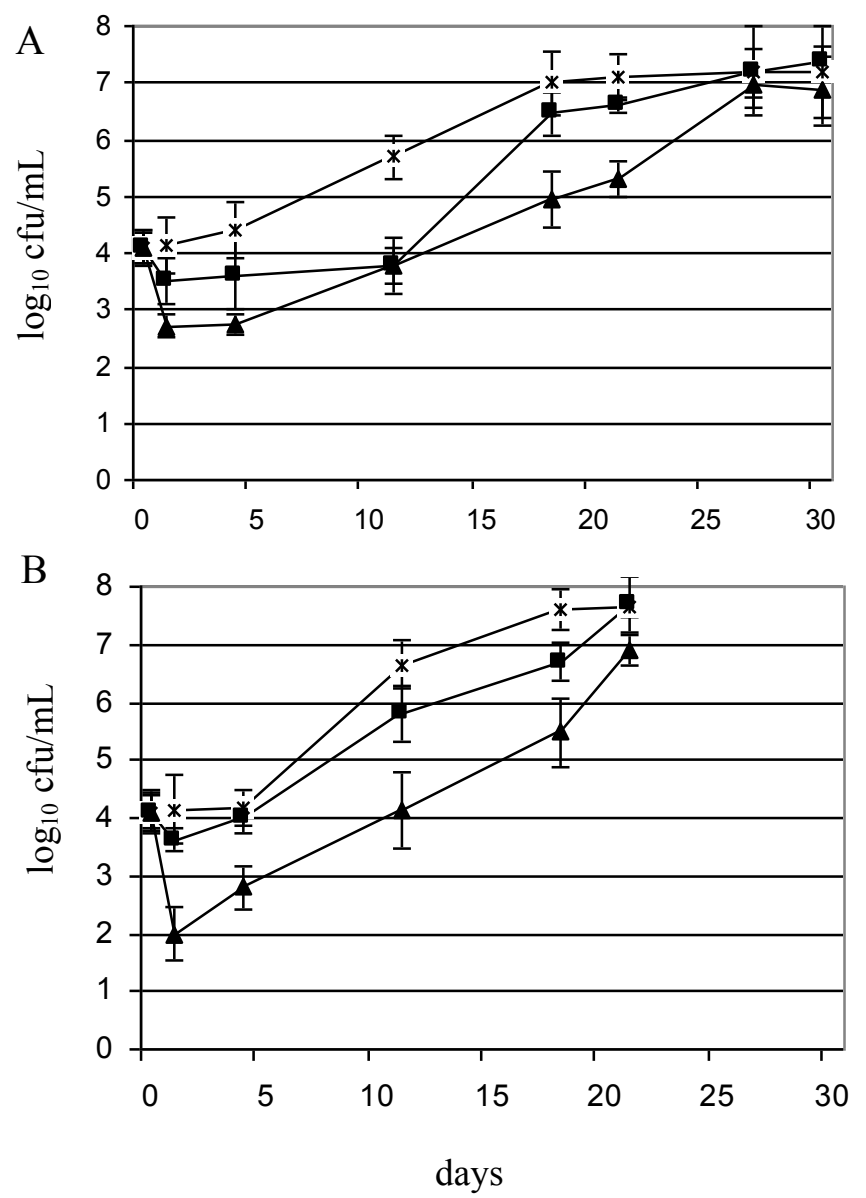

FIGURE 2

LAB population measured during a red grape microvinification adding 0 (cross), 200 (square) and 400 (triangle) $\mathrm{mg} / \mathrm{L}$ of lysozyme to grape must at $\mathrm{pH}$ 3.20 (A) and 3.60 (B) contaminated with L. brevis DB12 and O. oeni DB3. Bars are standard deviations. 


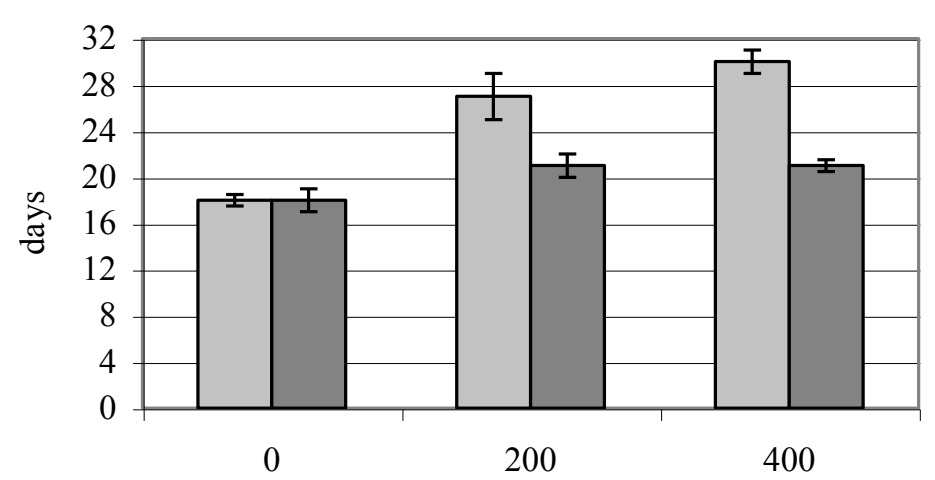

lysozyme $(\mathrm{mg} / \mathrm{L})$

FIGURE 3

Duration (days) of malolactic fermentation in red grape microvinification from adding 0,200 and $400 \mathrm{mg} / \mathrm{L}$ of lysozyme to the grape must, at $\mathrm{pH} 3.20$ (light grey) and 3.60 (dark grey), contaminated with L. brevis DB12 and O. oeni DB3. Bars are standard deviations.
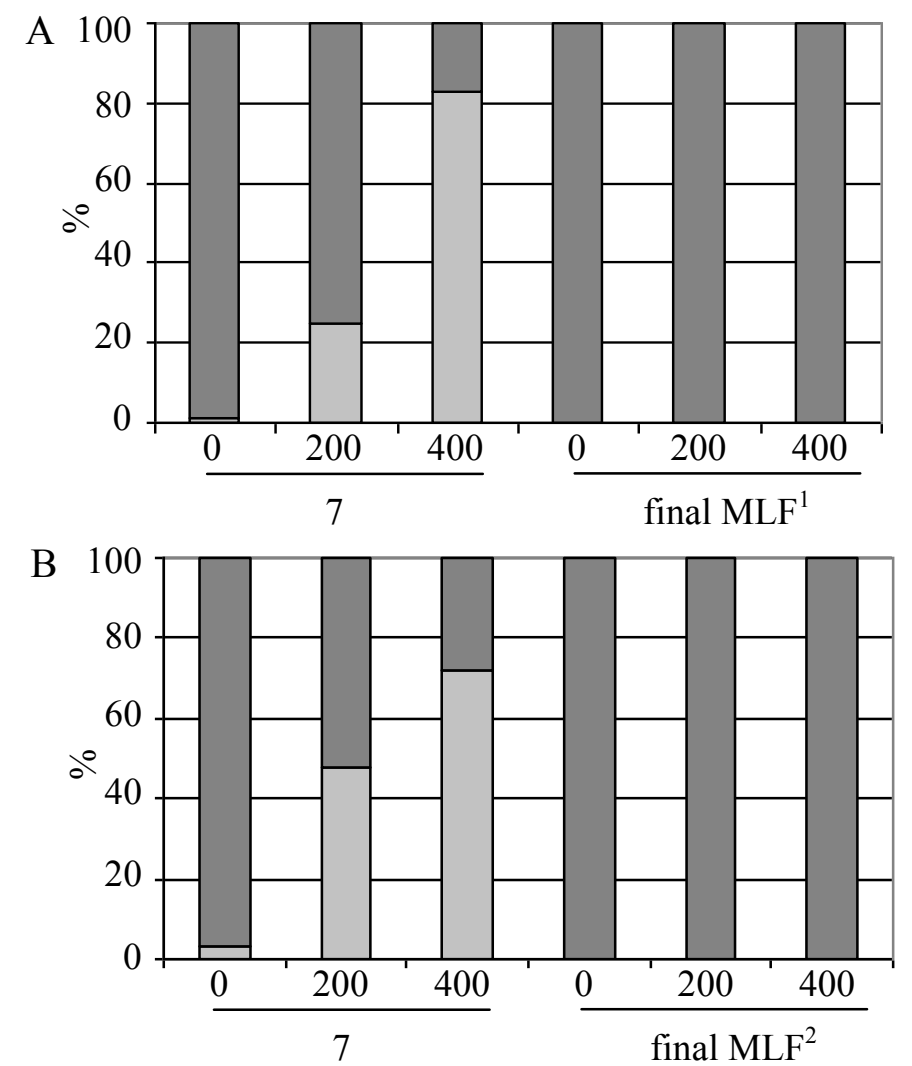

FIGURE 4

Percentage of L. brevis DB12 (light grey) and O. oeni DB3 (dark grey) determined after seven days and at final MLF in the microvinification of red grape must at pH 3.20 (A) and 3.60 (B), treated with 0,200 and $400 \mathrm{mg} / \mathrm{L}$ of lysozyme.

${ }^{1}$ after 18,27 and 30 days for trials with 0,200 and $400 \mathrm{mg} / \mathrm{L}$ of lysozyme
${ }^{2}$ after 18,21 and 21 days for trials with 0,200 and $400 \mathrm{mg} / \mathrm{L}$ of lysozyme and $300 \mathrm{mg} / \mathrm{L}$ respectively. Alcoholic fermentation (AF) was induced by inoculating a commercial yeast (VRB, Lallemand) and monitored by ethanol production and sugar consumption. Spontaneous MLF was monitored by L-malic acid depletion and the LAB population was enumerated by plate counts. Must-wine aliquots from the dilution series were plated out on FT80 pH 5.3 agar containing $0.01 \%$ actidione (Fluka, Seelze, Germany). The plates were incubated anaerobically for one week at $28^{\circ} \mathrm{C}$, using an Anaerocult A kit (Merck, Darmstadt, Germany). MLF was considered terminated when the L-malic acid content was less than $0.10 \mathrm{~g} / \mathrm{L}$.

\section{Assay on sensitivity of LAB to lysozyme}

The assay on the sensitivity of LAB to lysozyme was carried out according to Delfini et al. (2004), with some modifications. Cells, from pre-culture grown in FT80 $\mathrm{pH} 5.3$ (without lysozyme) at $28^{\circ} \mathrm{C}$ were harvested at the initial stationary phase and used to inoculate $10 \mathrm{~mL}$ of fresh FT80 medium containing 0, 100, 200 and $500 \mathrm{mg} / \mathrm{L}$ of lysozyme. The inoculation size was approximately $10^{7} \mathrm{cfu} / \mathrm{mL}$. The tubes (in triplicate) were incubated at $28^{\circ} \mathrm{C}$ for $16 \mathrm{~h}$, then an aliquot of $1 \mathrm{ml}$ was centrifuged, washed twice with $0.9 \% \mathrm{NaCl}$ and inoculated in $9 \mathrm{~mL}$ of fresh FT80 medium. The growth was measured by measuring $\mathrm{OD}_{600}$ during the incubation at $28^{\circ} \mathrm{C}$ and it was expressed as a percentage with respect to the maximal $\mathrm{OD}_{600}$ obtained in the control tube (without lysozyme).

\section{Contamination of grape must and microvinifications}

The efficacy of lysozyme under winemaking conditions was evaluated using Corvina and Garganega as the red and white grape varieties respectively. After grape crushing, the musts were used as growth substrate for strain pre-culture. These musts were pasteurised in order to eliminate the indigenous microflora. The $\mathrm{pH}$ was corrected to 4.0 to favour rapid cell growth of the pre-cultures. Cells of L. brevis DB12 and O. oeni DB3, grown at $28^{\circ} \mathrm{C}$ for one week, were harvested and used to inoculate the musts (and pomaces in the red vinification). For both strains the size of inoculation was about $10^{4}$ and $10^{7} \mathrm{cfu} / \mathrm{ml}$ in the red and white microvinifications respectively. Trials were carried out in duplicate.

The must from Corvina grapes contained reducing sugars at $19.2^{\circ} \mathrm{Brix}$, total acidity of $6.56 \mathrm{~g} / \mathrm{L}$ as tartaric acid, acetic acid $0.03 \mathrm{~g} / \mathrm{L}$ and L-malic acid $1.72 \mathrm{~g} / \mathrm{L}$. The original $\mathrm{pH}$ of 3.19 was corrected to 3.60 in a fraction. The must from Garganega contained reducing sugars at $22.1^{\circ}$ Brix, total acidity of $6.18 \mathrm{~g} / \mathrm{L}$ as tartaric acid, acetic acid $0.05 \mathrm{~g} / \mathrm{L}$ and L-malic acid $1.91 \mathrm{~g} / \mathrm{L}$. In two fractions the original $\mathrm{pH}$ of 3.43 was corrected to 3.10 and 3.70 .

The volume of each trial was $5 \mathrm{~L}$ for both microvinifications. The AF was induced by inoculation with commercial yeast (VRB, Lallemand) and monitored by ethanol production and sugar consumption. The fermentation was conducted in a wine cellar without controlled temperature $\left(17-20^{\circ} \mathrm{C}\right)$.

\section{Lysozyme activity during red grape fermentation}

The fermentation of Cabernet Sauvignon grapes was carried out in the absence or presence of pomaces in order to evaluate the effect of wine polyphenols on lysozyme activity. At crushing, the pomaces were separated from the must and both fractions were divided into aliquots of $1.5 \mathrm{~L}$ containing only must (-GP) or must plus grape pomaces $(+\mathrm{GP})$. The grape must was composed of the 

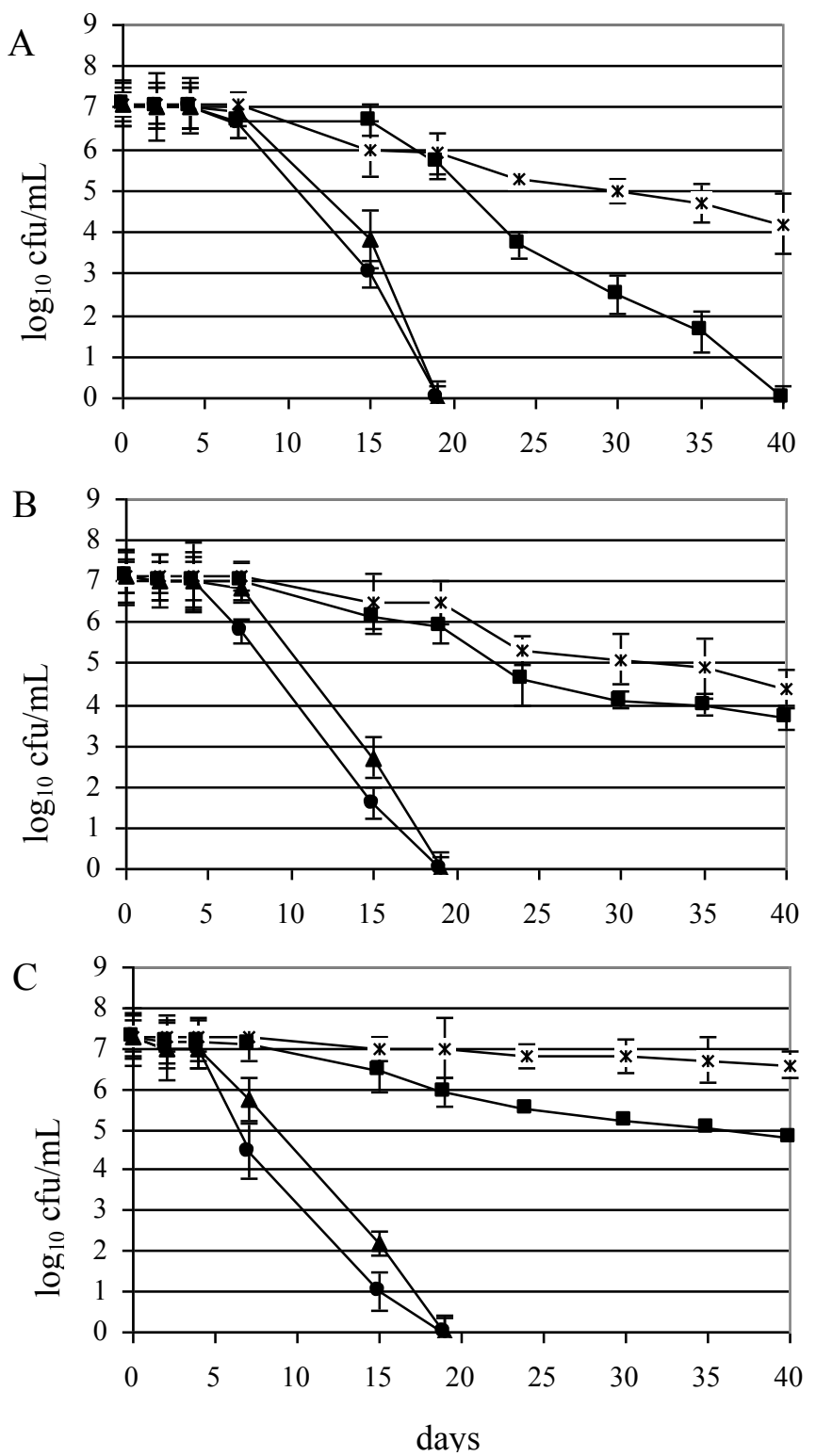

FIGURE 5

$\mathrm{LAB}$ population measured during a white grape microvinification after adding 0 (cross), 100 (square), 200 (triangle) and 300 (circle) $\mathrm{mg} / \mathrm{L}$ of lysozyme to the grape must, at $\mathrm{pH} 3.10$ (A), 3.40 (B) and 3.70 (C), contaminated with L. brevis $\mathrm{DB} 12$ and $O$. oeni DB3. Bars are standard deviations.

following: reducing sugars at $20.7^{\circ}$ Brix, total acidity $3.65 \mathrm{~g} / \mathrm{L}$ as tartaric acid, and $\mathrm{pH} 3.63$. After pasteurisation, $\mathrm{AF}$ was induced by inoculating with yeast (VRB, Lallemand) and monitored at $28^{\circ} \mathrm{C}$ by weight loss due to $\mathrm{CO}_{2}$ production. Trials were carried out in triplicate. Must-wine samples were collected at different times of fermentation, centrifuged to eliminate suspended solids and then analysed. To determine the remaining lysozyme activity, samples were diluted five- and 10-fold with buffer phosphate 50 $\mathrm{mM} \mathrm{pH} 6.0$ and added to a same volume of cell suspension. This suspension was obtained at the initial stationary phase from cells of L. brevis $\mathrm{DB} 12$ or O. oeni DB3 grown in FT80 pH 5.3, washed once with $\mathrm{NaCl} 0.9 \%$, once with buffer phosphate $50 \mathrm{mM} \mathrm{pH}$ 6.0 , and then resuspended in the same buffer to obtain an $\mathrm{OD}_{600}$ of about 1.0. The reaction mix (diluted must-wine sample and
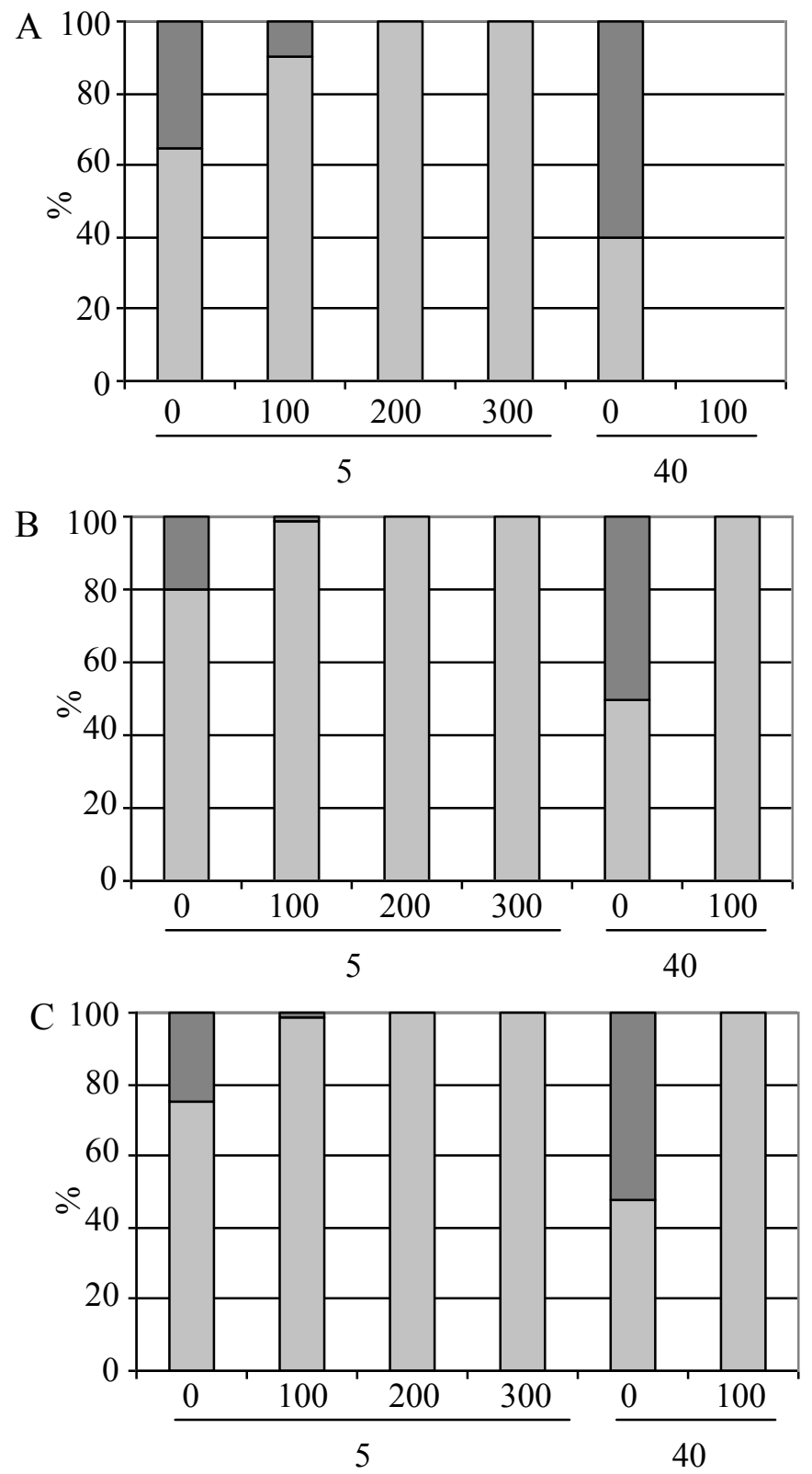

FIGURE 6

Percentage of L. brevis DB12 (light grey) and O. oeni DB3 (dark grey) determined after five and 40 days in the microvinification of white grape must at $\mathrm{pH} 3.10(\mathrm{~A}), 3.40(\mathrm{~B})$ and $3.70(\mathrm{C})$, treated with $0,100,200$, and $300 \mathrm{mg} / \mathrm{L}$ of lysozyme.

cell suspension, $1: 1)$ was incubated at $28^{\circ} \mathrm{C}$. Lysozyme activity was quantified by measuring the $\mathrm{OD}_{540}$ after 24 hours using a microplate spectrophotometer (Bio-rad, Hercules, CA).

\section{Lysozyme quantification by HPLC}

HPLC analysis was performed with a Beckman 125S HPLC pump system coupled with a spectrophotometric detector (Beckman Coulter, Inc., Fullerton, CA). The column was a Phenomenex Gemini C18, $5 \mu \mathrm{m}$ (Phenomenex, Torrance, CA). The solvents used were HPLC-grade acetonitrile (ACN), trifluoroacetic acid (TFA) and deionised distilled water. The HPLC method was used according to Daeschel et al. (2002): eluant A consisted of 1\% ACN, $0.2 \%$ TFA and $98.8 \%$ water, and eluant B consisted of $70 \%$ ACN, $0.2 \%$ TFA and $29.8 \%$ water. The must and wine samples were filtered with MiniSart RC15 syringe filters (Sartorius, 
Goettingen, Germany) before injection. The sample volume injected was $20 \mu \mathrm{L}$ and the flow rate was $1 \mathrm{~mL} / \mathrm{min}$. The solvent gradient consisted of four steps: at $\min 8$, solvent B from 0 to $45 \%$ in $5 \mathrm{~min}$; at $\operatorname{min~} 13$, solvent B from 45 to $47 \%$ in $2 \mathrm{~min}$; at min 15 , solvent $\mathrm{B}$ from 47 to $100 \%$ in $15 \mathrm{~min}$; at min 30 the solvent B returns to $0 \%$ in $5 \mathrm{~min}$ and the run time stops after 35 minutes. Detection was measured by absorbance at $280 \mathrm{~nm}$ and the lysozyme retention time was between $19.5 \mathrm{~min}$ and $20.7 \mathrm{~min}$. Lysozyme standards were prepared by solubilisation in water and made from 10 to $500 \mathrm{mg} / \mathrm{L}$.

\section{Statistical treatment of data}

Independent trials were conducted in duplicate for the micrivinifications and in triplicate for the lysozyme sensitivity assays and the red grape fermentation; the values reported in the tables and figures are means of two and three determinations \pm standard deviation respectively. Data from the red grape fermentation were analysed statistically by applying the T-test using the Graphpad Instat 3.0 program (Graphpad Software Inc., San Diego, CA).

\section{RESULTS}

\section{Efficacy of lysozyme against spontaneous LAB}

The effects of lysozyme on the spontaneous LAB present in the grape must were evaluated during a red and a white vinification to produce Valpolicella and Soave wine respectively. Growth kinetics differed strongly between the two types of vinification (Fig. 1). In the red vinification the cell population decreased just after the addition of lysozyme, but bacterial re-growth was observed within a few days. In the trials with $150 \mathrm{mg} / \mathrm{L}$ lysozyme, the LAB rapidly reached the same cell concentration as that measured in the control, while recovery was slower in those with $300 \mathrm{mg} / \mathrm{L}$. As a consequence, the completion of spontaneous MLF was delayed by 10 days only in the latter, while the addition of 150 $\mathrm{mg} / \mathrm{L}$ was ineffective (MLF lasted 20 days in the trials without and with $150 \mathrm{mg} / \mathrm{L}$ of lysozyme, while the fermentation lasted 30 days in the trials with $300 \mathrm{mg} / \mathrm{L}$ ). Differently from situation in the red vinification, spontaneous MLF was completely hindered by lysozyme in the white vinification due to the rapid mortality of the LAB population, even at also the lowest dosage (Fig. 1). In the control trials, MLF terminated after 25 days. In both vinifications the species $O$. oeni dominated the spontaneous populations, as revealed by species-specific PCR carried out on LAB isolated from trials treated and not treated with lysozyme (data not shown).

\section{Assay on sensitivity of LAB strains to lysozyme}

Different sensitivity of the indigenous LAB strains to lysozyme (Table 1) was observed. L. plantarum strains displayed high resistance, since contact with $500 \mathrm{mg} / \mathrm{L}$ lysozyme determined a delay of only a few hours in reaching 50 and $100 \%$ of growth with respect to the control. L. brevis DB12 displayed less resistance among the Lactobacillus spp. strains, while the growth of $O$. oeni DB3 was strongly delayed and contact with $500 \mathrm{mg} / \mathrm{L}$ caused a total suppression of its population. L. brevis DB12 and O. oeni DB3 were taken as representative strains of lysozyme-sensitive spontaneous wine bacteria.

\section{Effect of lysozyme in microvinification}

Lysozyme efficacy in controlling the growth of L. brevis DB12 and O. oeni DB3 strains, inoculated on grape must, varied according to the type of vinification, confirming what has been observed in previous vinifications (Gerbaux et al., 1999).

In the red microvinification the treatment of grape musts at $\mathrm{pH}$ 3.20 and 3.60 with lysozyme (200 and $400 \mathrm{mg} / \mathrm{L}$ ) caused partial mortality of the LAB, followed by a rapid re-growth (Fig. 2). Lysozyme addition did not prevent the total depletion of L-malic acid (Fig. 3): at $\mathrm{pH} \mathrm{3.60,} \mathrm{the} \mathrm{MLF} \mathrm{terminated} \mathrm{earlier} \mathrm{than} \mathrm{at}$ $\mathrm{pH}$ 3.20. Microbial analysis revealed that MLF was carried out by $O$. oeni $\mathrm{DB} 3$ in all the trails, since its population dominated the wines at the end of fermentation (Fig. 4). Lysozyme caused only a transitory reduction in $O$. oen $i \mathrm{DB} 3$, because this species dominated at the end of MLF. In contrast, L. brevis DB12 persisted at the beginning of the fermentation, but its population subsequently disappeared (Fig. 4).

In the white microvinification, the addition of 200 and 300 $\mathrm{mg} / \mathrm{L}$ of lysozyme completely inhibited the LAB population, with similar kinetics irrespective of the $\mathrm{pH}$ of the grape must (Fig. 5). In these trials the completion of MLF was hindered, while L-malic acid depletion was completed in the controls (after 38, 34 and 14 days at $\mathrm{pH} 3.10,3.40$ and 3.70, respectively). Total mortality of the LAB was also observed in grape must at $\mathrm{pH} 3.10$ treated with $100 \mathrm{mg} / \mathrm{L}$ of lysozyme, but not in the other musts. L. brevis DB12 dominated in all the trials treated with lysozyme, while $O$. oeni DB3 was suppressed after just five days, persisting only in the controls (Fig. 6).

\section{TABLE 1}

Time (hours) of delay, with respect to the control (without lysozyme), necessary to obtain 50 and $100 \%$ growth in FT80 medium pH 5.3 of LAB strains that remained in contact with lysozyme $(100,200$ and $500 \mathrm{mg} / \mathrm{L})$ for $16 \mathrm{~h}$.

\begin{tabular}{|c|c|c|c|c|c|c|}
\hline & \multicolumn{3}{|c|}{$50 \%$} & \multicolumn{3}{|c|}{$100 \%$} \\
\hline & 100 & 200 & 500 & 100 & 200 & 500 \\
\hline L. plantarum $\mathrm{DB} 7$ & $2 \pm 0$ & $7 \pm 1$ & $12 \pm 1$ & $0 \pm 0$ & $5 \pm 1$ & $10 \pm 2$ \\
\hline L. plantarum DB13 & $5 \pm 0$ & $5 \pm 1$ & $5 \pm 1$ & $0 \pm 0$ & $0 \pm 0$ & $2 \pm 0$ \\
\hline L. hilgardii DB19 & $5 \pm 1$ & $5 \pm 1$ & $10 \pm 2$ & $4 \pm 1$ & $30 \pm 2$ & $35 \pm 4$ \\
\hline L. brevis DB12 & $5 \pm 0$ & $20 \pm 2$ & $30 \pm 2$ & $24 \pm 4$ & $36 \pm 4$ & $46 \pm 4$ \\
\hline O. oеni $\mathrm{DB} 3$ & $19 \pm 2$ & $40 \pm 2$ & $\mathrm{ng}^{1}$ & $56 \pm 4$ & $76 \pm 8$ & ng \\
\hline
\end{tabular}

${ }^{1}$ not grown 
TABLE 2

Results of red grape fermentation carried out in absence (-GP) and presence (+GP) of grape pomaces. Lysozyme activity against $L$. brevis DB12 and $O$. oeni $\mathrm{DB} 3$ was measured as percent lysis.

\begin{tabular}{|c|c|c|c|c|c|c|}
\hline & & \multicolumn{5}{|c|}{ Days of alcoholic fermentation } \\
\hline & & $\mathbf{0}$ & 2 & 4 & 6 & 10 \\
\hline \multicolumn{7}{|l|}{ Lysozyme activity (\%) } \\
\hline \multirow[t]{2}{*}{ L. brevis $\mathrm{DB} 12$} & $-\mathrm{GP}$ & $25 \pm 2^{* * 1}$ & $22 \pm 3^{* *}$ & $22 \pm 1^{* *}$ & $21 \pm 0^{* *}$ & $20 \pm 1^{* *}$ \\
\hline & $+\mathrm{GP}$ & $13 \pm 1$ & $3 \pm 1$ & $3 \pm 0$ & $0 \pm 0$ & $0 \pm 0$ \\
\hline \multirow[t]{2}{*}{ O. oeni DB3 } & $-\mathrm{GP}$ & $58 \pm 2^{* *}$ & $45 \pm 2^{* *}$ & $43 \pm 2^{* * *}$ & $40 \pm 2^{* *}$ & $36 \pm 3^{* * *}$ \\
\hline & $+\mathrm{GP}$ & $49 \pm 1$ & $34 \pm 2$ & $11 \pm 1$ & $0 \pm 0$ & $0 \pm 0$ \\
\hline \multirow[t]{2}{*}{ Residual lysozyme (mg/L) } & $-\mathrm{GP}$ & $115 \pm 13$ & $136 \pm 10^{* *}$ & $124 \pm 16^{* *}$ & $109 \pm 14^{* *}$ & $135 \pm 18^{* *}$ \\
\hline & $+\mathrm{GP}$ & $117 \pm 19$ & $49 \pm 5$ & $0 \pm 0$ & $0 \pm 0$ & $0 \pm 0$ \\
\hline \multirow[t]{2}{*}{$\mathrm{CO}_{2}$ produced $(\%)$} & $-\mathrm{GP}$ & $0 \pm 0$ & $19 \pm 1$ & $63 \pm 3$ & $92 \pm 1^{*}$ & $100 \pm 1$ \\
\hline & $+\mathrm{GP}$ & $0 \pm 0$ & $17 \pm 2$ & $65 \pm 1$ & $96 \pm 1$ & $100 \pm 0$ \\
\hline \multirow[t]{2}{*}{ Total polyphenols $(\mathrm{mg} / \mathrm{L})$} & $-\mathrm{GP}$ & $536 \pm 68^{*}$ & $540 \pm 85^{* *}$ & $384 \pm 34^{* *}$ & $390 \pm 8^{* *}$ & $324 \pm 28^{* *}$ \\
\hline & $+\mathrm{GP}$ & $864 \pm 127$ & $1540 \pm 155$ & $2020 \pm 14$ & $2200 \pm 42$ & $2715 \pm 219$ \\
\hline \multirow[t]{2}{*}{ Total anthocyanins $(\mathrm{mg} / \mathrm{L})$} & $-\mathrm{GP}$ & $66 \pm 1^{* * *}$ & $56 \pm 8^{* *}$ & $50 \pm 9^{* * *}$ & $45 \pm 5^{* *}$ & $38 \pm 8^{* *}$ \\
\hline & $+\mathrm{GP}$ & $206 \pm 20$ & $816 \pm 5$ & $1043 \pm 11$ & $1078 \pm 3$ & $967 \pm 10$ \\
\hline \multirow[t]{2}{*}{ Colour intensity } & $-\mathrm{GP}$ & $1.5 \pm 0.1^{* *}$ & $1.4 \pm 0.1^{* * *}$ & $1.3 \pm 0.2^{* *}$ & $0.9 \pm 0.3^{* *}$ & $0.8 \pm 0.0^{* *}$ \\
\hline & $+\mathrm{GP}$ & $3.9 \pm 0.1$ & $9.5 \pm 1.0$ & $16.7 \pm 0.1$ & $18.0 \pm 0.6$ & $19.2 \pm 0.2$ \\
\hline
\end{tabular}

$1^{*, * *}$, significantly different for $p<0.05$ and 0.01 respectively, between $-\mathrm{GP}$ and $+\mathrm{GP}$ values

\section{Lysozyme activity with and without grape pomaces}

The fermentation of red grapes was carried out in the absence and presence of grape pomaces in order to evaluate the effect of wine polyphenols released during alcoholic fermentation on lysozyme activity.

The presence or absence of grape pomaces influenced lysozyme activity against two strains (Table 2). Without grape pomaces (-GP), the lysis of L. brevis DB12 and O. oeni DB3 decreased by up to 5 and $22 \%$ respectively. With grape pomaces (+GP), the lysozyme had less efficacy and the activity was completely inhibited before the end of AF. The quantification of residual lysozyme by HPLC revealed its disappearance in trials containing GP, starting after just six days of fermentation, while no significant variation in its amount was observed in those without GP.

\section{DISCUSSION}

The results obtained with the Valpolicella vinification confirmed previous observations by Gerbaux et al. (1999), who showed that $500 \mathrm{mg} / \mathrm{L}$ lysozyme added to Pinot Noir before AF was hardly effective or ineffective against LAB. These observations were a starting point for further study on its efficacy under red winemaking conditions.

The red wine microvinification demonstrated that lysozyme addition was not enough to completely control LAB growth. In particular, the differences observed between the $\mathrm{pH} 3.20$ and 3.60 trials were attributed mainly to wine acidity rather that to the presence of lysozyme. Despite this muramidase being more active at high than at low $\mathrm{pH}$, its inhibitory effect decreased under environmental conditions favourable to the growth of spoilage
LAB. This evidence was confirmed by the microvinification of white grapes, where the addition of $100 \mathrm{mg} / \mathrm{L}$ of lysozyme at $\mathrm{pH} 3.70$ prolonged, but did not stop, the MLF carried out by $L$. brevis DB12 with respect to the control. According to Gao et al. (2002), $125 \mathrm{mg} / \mathrm{L}$ of lysozyme was effective against L. brevis in Chardonnay ( $\mathrm{pH} 3.8$ ) inoculated with a similar concentration to the one we used in the white microvinification. Taking into account that these high levels of grape contamination $\left(10^{7}-10^{8} \mathrm{cfu} /\right.$ $\mathrm{mL}$ ) do not occur frequently in standard winemaking conditions, the addition of 100 to $150 \mathrm{mg} / \mathrm{L}$ could be enough to prevent any attack of spoilage LAB during white grape fermentation.

The reduction of lysozyme activity in red winemaking is determined by the binding properties of wine phenols to proteins (Hagerman \& Butler, 1981). The results of the red grape fermentation trials demonstrated that the presence of grape pomaces affected lytic activity against the L. brevis and O. oeni strains. A positive evaluation of the efficacy of lysozyme in red winemaking was expressed by Delfini et al. (2004), who observed the behaviour of $O$. oeni and L. hilgardii remaining in contact with the enzyme for $16 \mathrm{~h}$ in Barbera must. Nevertheless, prolonged contact of the muramidase with wine LAB, as occurs during grape fermentation, determines a gradual reduction in lytic activity due to the binding effects of wine phenols to lysozyme, as we observed in the red grape fermentation. The rate of lysozyme disappearance during AF was in relation to the increase in wine phenols extracted during the vinification. A large decrease in the amount of lysozyme in the red wine (after AF) was observed just a few days after its addition (Daeschel et al., 2002, Tirelli \& De Noni, 2007). Hence, the timing of its use assumes relevance to prevent $\mathrm{LAB}$ contamination in red winemaking. Lysozyme added 
to grape must could cause a significant reduction in cells due to the low polyphenol content, as we observed at the beginning of the Valpolicella vinifications. Nevertheless, the re-growth rate is dependent on parameters that influence LAB growth, such as $\mathrm{pH}$ and the wine polyphenol composition responsible for the amount of insoluble enzyme. According to Tirelli and De Noni (2007), enzyme concentrations unable to affect $\mathrm{LAB}$ were found in wine when the flavonoid content exceeded $50 \mathrm{mg} / \mathrm{L}$. This concentration is above the typical level of flavonoids in white table wine (40$45 \mathrm{mg} / \mathrm{L}$ ) and well below the typical level in red table wine (1300-1500 mg/L) (Waterhouse, 2002). The inhibitory effects of wine phenols were clearly demonstrated by the quantification of the residual lysozyme by HPLC, despite the described method (Daeschel et al., 2002) having a detection limit (5-10 mg/L) higher than that of the enzymatic assay (Table 2).

The rapid combination of lysozyme with must colloids and suspended solids determined a significant reduction in the free enzyme just after its addition, as previously demonstrated (Delfini et al., 2004). Then, the further loss of lysozyme during AF in the presence of grape pomaces explained the decrease in activity against $\mathrm{LAB}$ strains. At the end of AF, the action of lysozyme against LAB could be strongly compromised when the soluble polyphenols are completely extracted.

LAB have different sensitivities to lysozyme and muramidase effects in winemaking, depending on the species/strain composition of the spontaneous population (Delfini et al., 2004; Blättel et al., 2009).

It was possible to analyse the kinetics of the cell populations of LAB strains that are differently sensitive to lysozyme by inoculating $L$. brevis $\mathrm{DB} 12$ and $O$. oeni $\mathrm{DB} 3$, mimicking a possible microbial contamination occurring during grape crushing. The transitory reduction in the $O$. oen $i \mathrm{DB} 3$ population with respect to L. brevis DB12, observed in the red wine microvinification (Figure 4), was due to its low resistance to the muramidase. The inhibition of lysozyme activity caused by wine phenol did not prevent the re-growth of the $O$. oeni population. However, the ineffectiveness of lysozyme can be supposed against resistant strains, such as $L$. plantarum DB7 and DB13 under similar experimental conditions to those utilised in this work.

The benefits of lysozyme usage after AF due to the ensured successful implantation of $O$. oeni MLF starter culture, as described by Isabel et al. (2009), are probably explained by the concurrence of reduced lytic activity and the different cell concentration between the inoculated culture and indigenous strains. Nevertheless, these benefits could be reduced greatly in the case that a high density of spontaneous malolactic bacteria are present at the end of AF.

In conclusion, this study used a practical approach to highlight the varying efficacy of lysozyme against LAB in red and white vinifications. New information has been presented about the opportunity of using this antimicrobial agent in grape must fermentation. Although lysozyme could be a valid alternative to $\mathrm{SO}_{2}$ for controlling LAB in white winemaking, the same cannot be said for red winemaking. Many factors concur to inhibit lysozyme activity in red winemaking, to the extent that its use could even be without effect. A better understanding is needed of the mechanisms involved in the interaction between lysozyme and red must/wine components ( $\mathrm{pH}$, polyphenols, $\mathrm{SO}_{2}$, ethanol, etc.).
From a technological point of view, the elaboration of prediction models will be important to define the relationship between wine composition and lysozyme dosage.

\section{LITERATURE CITED}

Bartowsky, E.J. \& Hensche, P.A., 2004. The "buttery" attribute of wine-diacetyldesirability, spoilage and beyond. Int. J. Food Microbiol. 96, 235-252.

Bartowsky, E.J., 2009. Bacterial spoilage of wine and approaches to minimize it. Lett. Appl. Microbiol. 48, 149-156.

Blättel, V., Wirth, K., Claus, H., Schlott, B., Pfeiffer, P. \& König, H., 2009. A lytic enzyme cocktail from Streptomyces sp. B578 for the control of lactic and acetic acid bacteria in wine. Appl. Microbiol. Biotechnol. 83, 839-848.

Cavin, J.-F., Prévost, H., Lin, J., Schmitt, P. \& Divies, C., 1989. Medium for screening Leuconostoc oenos strain defective in malolactic fermentation. Appl. Environ. Microbiol. 55, 751-753.

Daeschel, M.A., Musafija-Jeknic, T., Bizzarri, D. \& Volla, A., 2002. Highperformance liquid chromatography analysis of lysozyme in wine. Am. J. Enol. Vitic. 53, 154-157.

Delfini, C., Cersosimo, M., Del Prete, V., Strano, M., Gaetano, G., Pagliara, A. \& Ambrò, S., 2004. Resistance screening essay of wine lactic acid bacteria on lysozyme: efficacy of lysozyme in unclarified grape musts. J. Agric. Food Chem. $52,1861-1866$.

Gao, C.Y., Zhang, G., Krentz, S., Darius, S., Power, J. \& Lagarde, G., 2002. Inhibition of spoilage lactic acid bacteria by lysozyme during wine alcoholic fermentation. Aust. J. Grape Wine Res. 8, 76-83.

Gerbaux, V., Meistermann, E., Cottereau, P.H, Barrière, C., Cuinier, C., Berger, J.L. \& Villa, A., 1999. Use of lysozyme in enology. Bull. OIV 819-820, 348-373.

Glories, Y., 1979. Reserches sur la matìere colorante des vins rouges. Bull. Soc. Chim. France 9, 139-191.

Hagerman, A.E. \& Butler, L.G., 1981. The specificity of proanthocyanidin-protein interaction. The J. Biol. Chem. 256, 4494-4497.

Hughey, V.L. \& Johnson, E.A., 1987. Antimicrobial activity of lysozyme against bacteria involved in food spoilage and food-borne disease. Appl. Environ. Microbiol. 53, 2165-2170.

Isabel, L., Santamaria, P., Tenorio, C., Garijo, P., Gutierrez, A.R. \& Lopez, R., 2009. Evaluation of lysozyme to control vinification process and histamine production in Rioja wines. J. Microbiol. Biotechnol. 19, 1005-1012.

Kirschner, S., Belloni, B., Kugler, C., Ring, J. \& Brockow, K., 2009. Allergenicity of wine containing processing aids: a double-blind, placebo-controlled food challenge. J. Investig. Allergol. Clin. Immunol. 19, 210-217.

Ough, C.S. \& Amerine, M.A., 1988 (2nd ed). Methods Analysis of Musts and Wines. Wiley \& Sons, Chichester.

Ribéreau-Gayon, P., Dubourdieu, D., Donèche, B. \& Lonvaud-Funel, A., 2006 (2nd ed). Handbook of Enology: The Microbiology of Wine and Vinifications. Wiley \& Sons, Chichester.

Singleton, V. \& Rossi, J.A., 1965. A colorimetric of total phenolics with phosphomolybdic-phosphotungstic reagents. Am. J. Enol. Vitic. 16, 144-158.

Sonni, F., Cejudo Bastante, M.J., Chinnici, F., Natali, N. \& Riponi, C., 2009. Replacement of sulfur dioxide by lysozyme and oenological tannins during fermentation: influence on volatile composition of white wines. J. Sci. Food Agric. 89, 688-696.

Tirelli, A. \& De Noni, I., 2008. Evaluation of lysozyme stability in young red wine and model systems by a validated HPLC method. Food Chem. 105, 1564-1570.

Torriani, S., Felis, G.E. \& Dellaglio, F., 2001. Differentiation of Lactobacillus plantarum, L. pentosus, and L. paraplantarum by recA gene sequence analysis and multiplex PCR assay with recA gene-derived primers. Appl. Environ. Microbiol. $67,3450-3454$

Waterhouse, A.L., 2002. Wine phenolics. Ann. N. Y. Acad. Sci. 957, 21-36.

Weber, P., Steinhart, H. \& Paschke, A., 2007. Investigation of the allergenic potential of wines fined with various proteinogenic fining agents by ELISA. J. Agric. Food Chem. 55, 3127-3133.

Zapparoli, G., Torriani, S., Pesente, P. \& Dellaglio, F., 1998. Design and evaluation of malolactic enzyme gene targeted primers for rapid identification and detection of Oenococcus oeni in wine. Lett. Appl. Microbiol. 27, 243-246. 